\section{Inflammatory bowel disease and epithelial barrier function}

\begin{tabular}{|c|c|}
\hline $\begin{array}{l}\text { Inflammatory bowel disease } \\
\text { (IBD) occurs when the } \\
\text { epithelial cells lining the gut } \\
\text { become weakened, allowing } \\
\text { gut microbes to activate } \\
\text { immune cells. Gut barrier } \\
\text { weakening can be caused } \\
\text { by a loss of function of the } \\
\text { PTPN2 gene. Professor Declan } \\
\text { McCole of the University } \\
\text { of California, Riverside and } \\
\text { various collaborators have } \\
\text { extensively researched the } \\
\text { role of the epithelial barrier } \\
\text { in IBD, the role of the PTPN2 } \\
\text { gene, and potential targets } \\
\text { for future treatment of this } \\
\text { disease. The McCole group has } \\
\text { also demonstrated that low } \\
\text { gravity environments such as } \\
\text { outer space have a negative } \\
\text { and long-lasting effect on the } \\
\text { epithelial barrier. }\end{array}$ & $\begin{array}{l}\text { he cells that line the insides of } \\
\text { humana intestines (epithelial cells) } \\
\text { have an essential role to play in } \\
\text { forming a barrier against any possible } \\
\text { infectious agents that could be present } \\
\text { in food material, as well as helping to } \\
\text { break down food into nutrients that can } \\
\text { be absorbed, and taking up water to } \\
\text { prevent dehydration. They provide a } \\
\text { separative layer between the contents } \\
\text { of the intestine and the underlying } \\
\text { tissue and vasculature. Crohn's disease } \\
\text { and ulcerative colitis are both chronic } \\
\text { inflammatory conditions of the human } \\
\text { intestine and are collectively known as } \\
\text { inflammatory bowel disease (IBD), which } \\
\text { affects millions of people globally. An } \\
\text { early change in IBD is reduced function } \\
\text { of the intestinal epithelial barrier, which } \\
\text { allows gut bacteria to access intestinal } \\
\text { immune cellls and causes a cycle of } \\
\text { inflammation, further weakening the } \\
\text { intestinal barrier. This increase in intestina } \\
\text { permeability is commonly referred to as } \\
\text { leaky gut syndrome. }\end{array}$ \\
\hline
\end{tabular}

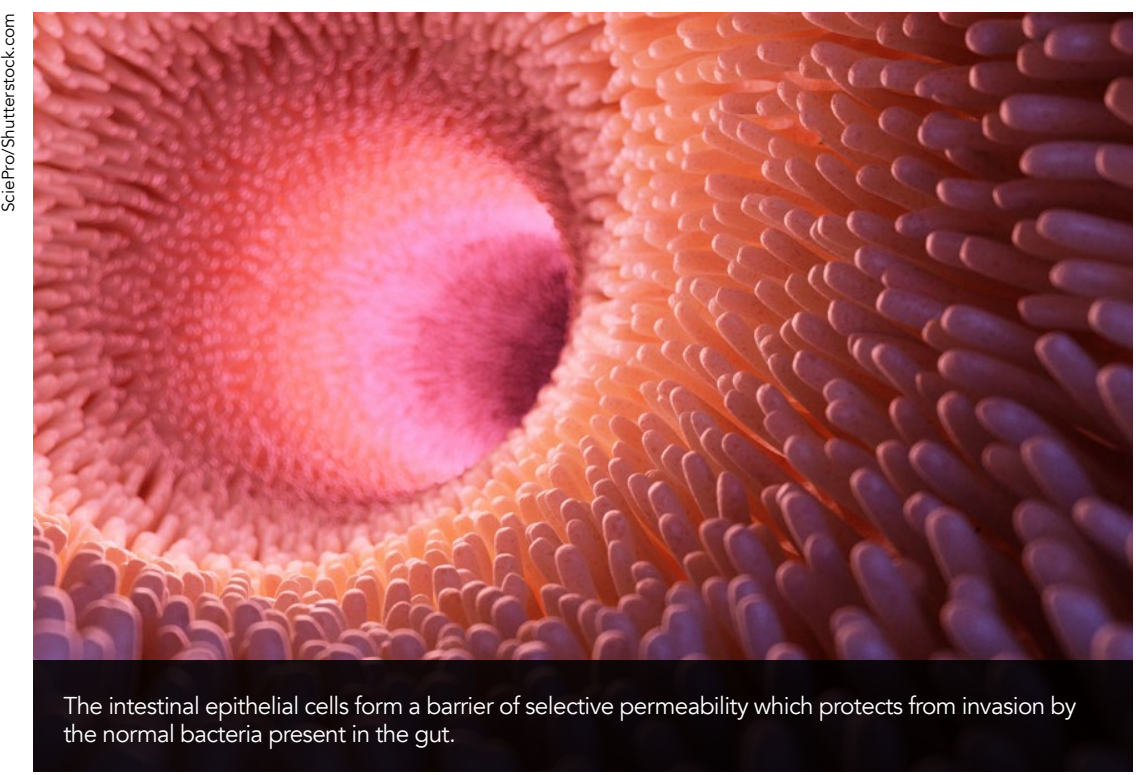

The causes of IBD are not fully understood, but genetics and changes in the natural gut microbiome the population of microorganisms such as bacteria) are known to be critically form a barier of selective permeability which protects from invasion by the normal bacteria present in the gut When the barrier is compromised, bacteria and their products can attack the cells and cause inflammation, which can (in severe cases) cause sepsis. Professor McCole has focused his research on these barrier cells and their role in chronic inflammatory gut conditions. The McCole group has also collaborated on studies into therapeutic avenues for IBD and the effect of low gravity environments on intestinal

PTPN2

The protein tyrosine phosphatase non-receptor type 2 (PTPN2) gene phosphatase (TCPTP). This protein is essential for regulation of inflammation. Loss of function of the PTPN2 gene is associated with several autoimmune diseases including Crohn's disease, diabetes and rheumatoid arthritis. The PTPN2 gene is therefore an important diseases of the immune system.

In 2009, the McCole group were the first to identify that absent function of this gene weakens the epithelial cell barrier. They have since built on this observation Meera Nair and Dr Michael Scharl, to demonstrate that PTPN2 controls the ulcerative colitis, coeliac disease, type 1 susceptibility marker for IBD and other alongside Dr Marianne Spalinger, Dr

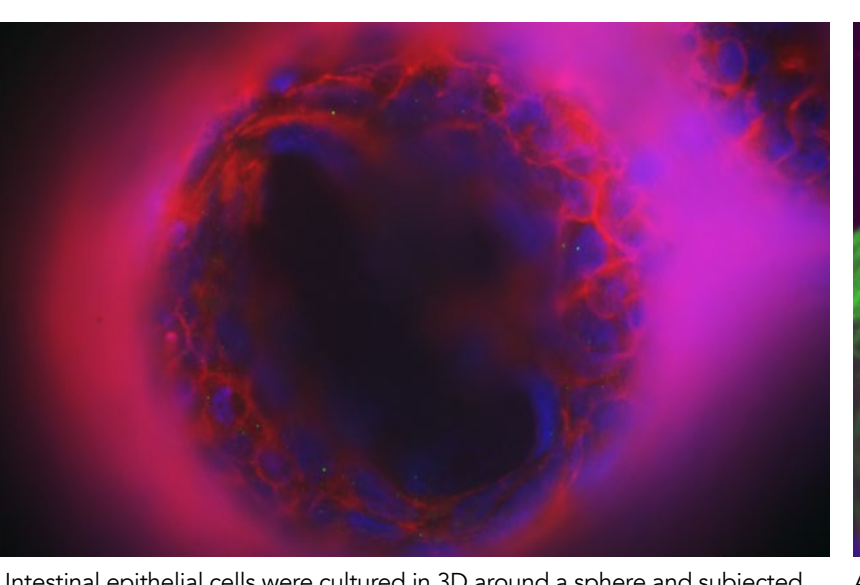

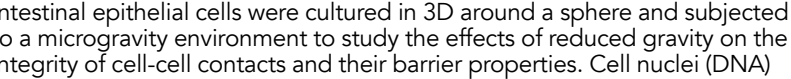

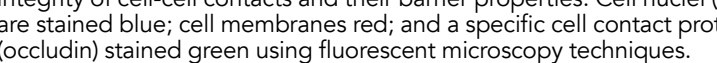
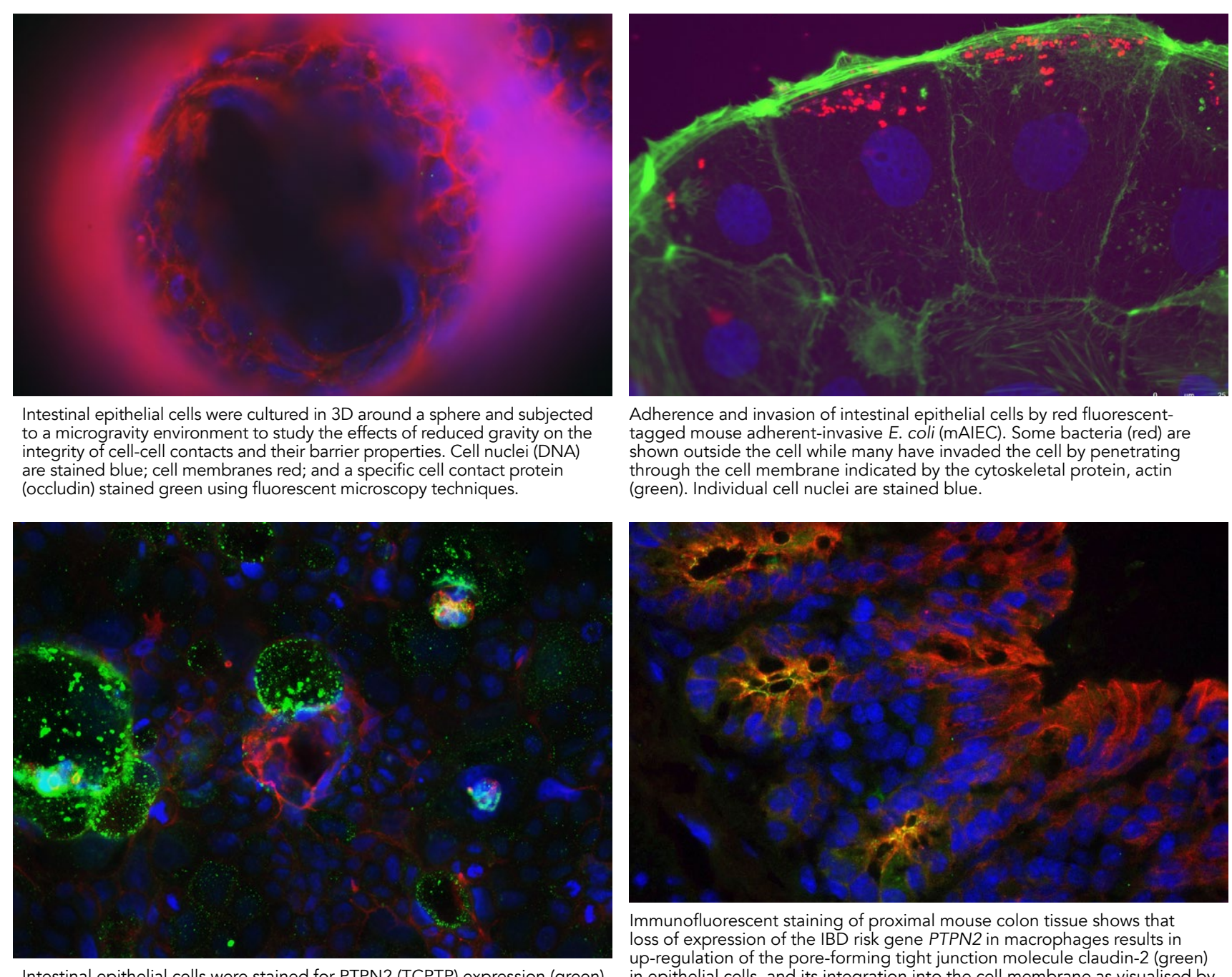

Adherence and invasion of intestinal epithelial cells by red fluorescent-
agged mouse adherent-invasive $E$. coli (mAIECC). Some bacteria (red) are shown outside the cell while many have invaded the cell by penetrating
through the cell membrane indicated by the cytoskeletal protein, actin

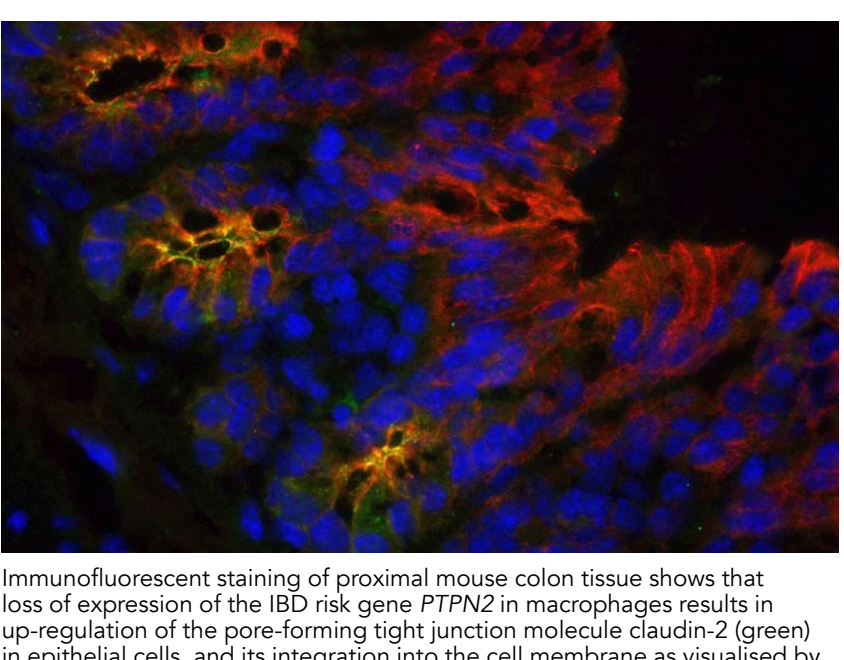

Intestinal epithelial cells were stained for PTPNN (TCPTP) express
Cell nuclei (DNA) are stained blue; cell membranes stained red.

(immune cells that eat bacteria and viruses) and intestinal epithelial cells to maintain the epithelial barrier and therefore a healhy intestine. It was also

\section{CLINICAL APPLICATIONS} Modulation of inflammation by TCPTP is partly via control of inflammatoy

inhibiting Janus kinase (JAK) enzymes promotes a more inflammatory gut with an absence of the PTPN2 gene have been gemenstrated to have both increased levels of inflammatory cytokines (substances produced by cells which promote inflammatory responses in other cells and uncontrolled inflammation. The disruption of the communication betwee intestinal epithelial cells and macrophag affects both the immune response and the integrity of the intestinal barrier. This research gives new insight into the role of genetic susceptibility in gut barier

Understan
loss of
highlight
es (substances
promote
in other cells)
mation. The
andition between
androphages
response and
inhal barrier. This
into the role
in tarrier

and signal transducer and activator of transcription (STAT) molecules. JAK-STAT signalling pathways can be activated by inflammatory cytokines such as interferon-gamma, which is associated with autoimm une diseases including IBD and coeliac disease. loss of PTPN2 function and IBD can
highlight areas for intervention to help
列 targeting the pathway between loss regulation and the ime epithelial barrier personalised treatment of IBD. Studies by the McCole group have shown that on $\begin{array}{ll}\text { PTPN2 function and IBD can } & \text { bacterial formulation } \\ \text { (which is approved for }\end{array}$ clinical treatment of
IBD patients following to reduce symptoms. Understanding the relationship between the activity of the PTPN2 gene and therefore improved the function of the pithelial barrier (2)

One recent study, in which the McCole group collaborated with Dr Adrian $G$. Butt, showed promising results for epithelial barrier maintenance in IBD patients treated with tofacitinib (the Tofacitinib is a JAK inhibitor, and therefore 
blocks the activity of JAK enzymes IBD. In this sudy stmate causing grow artificial human intestinal epithelial structures, which were then exposed to interferon-gamma, an inflammatory cytokine associated with IBD. It was shown that tofacitinib could actually restore the integrity of the damaged epithelial barrier. This was the first study to highlight the importance of the gut epithelial cells as a therapeutic target of tofacitinib (3).

\section{THE GUT MICROBIOM}

Changes to the normal gut microbiom are an important factor in the disease process of IBD. Environments which allow expansion of intestinal bacteria tha have the potential to attack the epithelia and pronression of IBD. In collabortion with microbiologists Dr James Borneman and DrAnsel Hsio The Mccle group investigated the relationship between PTPN2 and adherent-invasive $E$ coli (AIEC). AIEC is a specific type of $E$. coll bacteria which is known to colonise the intestines of sufferers of $I B D$, and is thought to be involved in the disease process as it increases the production of inflammatory cytokines as well as altering the regulation of the proteins forming junctions between epithelial cells (4).

Mice lacking the PTPN2 gene showed a greater population of a novel mouse AIEC when compared to mice with a functiona PTPN2 gene. This mouse AIEC showed with IBD in humans. This mo associated shown to not only increase the severity of colitis in mice, but also to prevent recovery from it. This study therefore demonstrated that the PTPN2 gene regulates the normal gut microbiome to protect against novel infectious agents; and consequently, loss of function of the PTPN2 gene contributes to an altered gut microbiome which allows the proliferation of an AIEC which can both initiate and worsen disease. Future research could build on these findings by using PTPN deficient mice as a model to study the relationship between host genetics and the gut microbiome. These studies have enabled the McCole group to build a more interconnected view of the delicate the gut mion the

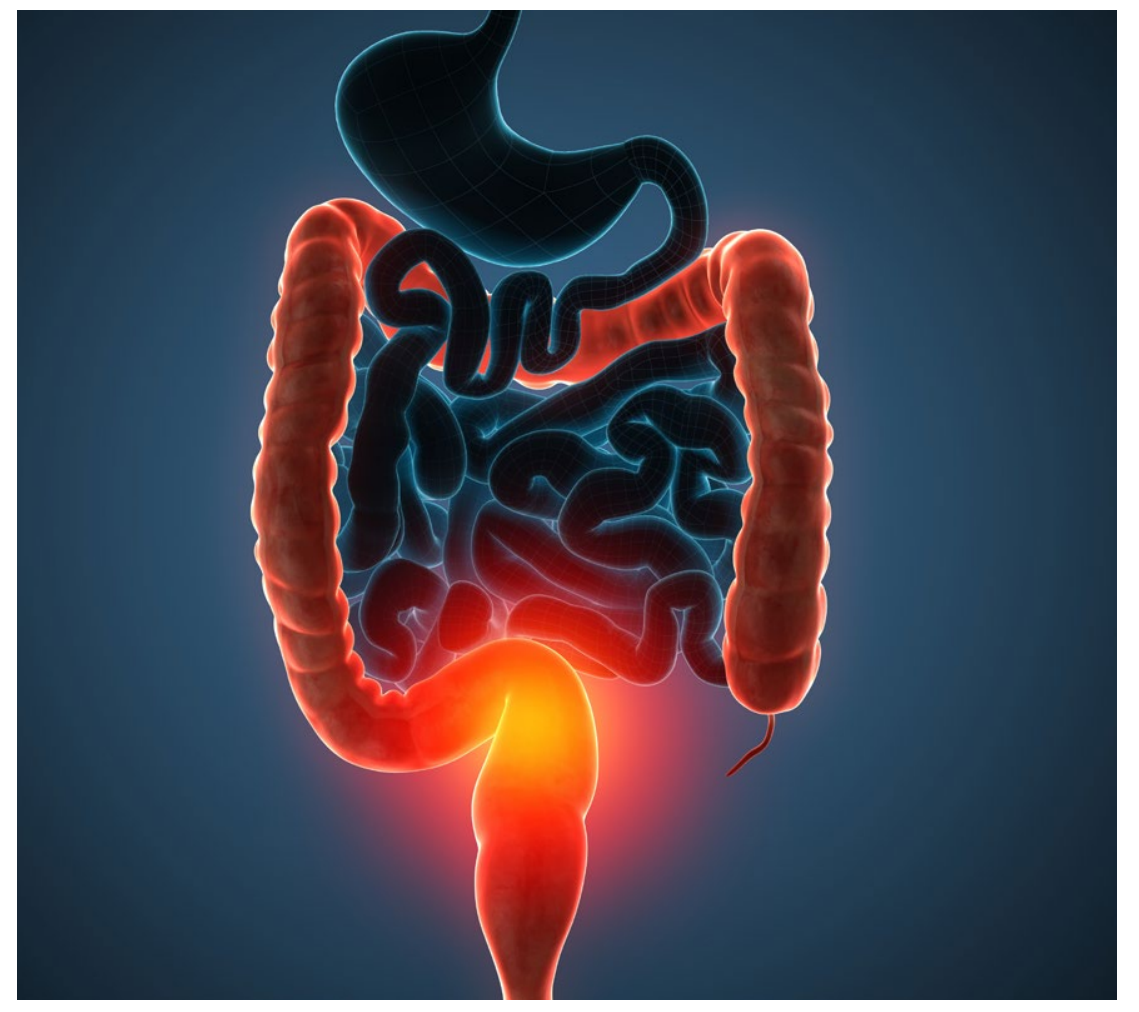

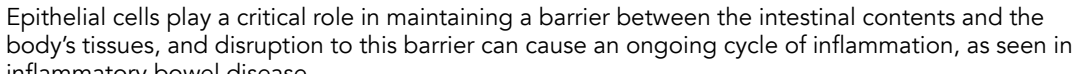

\section{Changes to the normal gut microbiome} are an important factor in the disease process of IBD.

of this balance can contribute to diseases such as IBD.

MICROGRAVITY

Professor McCole's group, together whevions lithe, investigated the microgravity (low gravity environments, as would be experienced in outer spact on the epithelial cell barrier (5). Previous studies in the field of space biology have demonstrated that microgravity can have a negative impact on the human immune system, via suppression of multiple immune cells. This study aime to assess the permeability of the epitheli infection in microgravity environments. Using a rotating bioreactor to create an enther epithelial cells were placed in simulated microgravity and then assessed for permeability. Simulated microgravity was show to cause disruption to the epichelal bacier. This reduced function returning to a normal gravity environment ncreasing their potential susceptibility to invasion of the epithelial cell barrier. This has long-termimplications for the gut eath of individuals undertaking missions tefects of low ravity human body can allow orgnisations such as NASA to better prepare and protect their astronauts.

\section{CONCLUSION} intestinal contents and the body's tissues, and disruption to this barrier can cause an ongoing cycle of inflammation. The barrier may be compromised by chronic disease such as IBD or by abnorma Underments such as microgravity. and envirng the effect of genetics barrier allows pon the epithelial cell areas to be targeted to relieve sic of symptoms of both acteve silferers intestinal disease.
Epithelial cells play a critical role in

\section{Behind the Research}

Professor Declan McCole

E: declan.mccole@ucr.edu T: +1 951 827-7785 W: https://profiles.ucr.edu/app/home/profile/dmccole

\section{Research Objectives}

Professor McCole's lab takes a multidisciplinary approach Prots of inflammation on epithelial barrier function.

\section{Detail}

Professor Declan McCole

900 University Avenue

Division of Biomedical Sciences

School of Medicine

University of California, Riverside

Riverside, CA 92521 USA

Bio

Dr McCole is a Professor of Biomedical Sciences at UCR School of Medicine. He obtained his B.Sc. and Ph.D.

in Pharmacology \& Veterinary Medical Research from

University College Dublin, Ireland. He was a postdoctora searcher and junior faculy at UC San Diego (Division of astroenterology) before joining UCR in 2013

Funding

NDK, NIAID, Crohn's and Colitis Foundation, American Gastroenterological Association, Pfizer Inc.

\section{Collaborators}

Dr Kim E. Prisk (UCSD)

- Dr Michael Scharl (University Hospital Zurich, Switzerland) - Dr Marianne Spalinger (UCR)

- Dr James Borneman (UC

- Dr Ansel Hsiao (UCR)

- Dr Adrian G. Butt (University of Otago, New Zealand)

\section{UG RIVERSIDE}

School of Medicine

\section{References}

1. Spalinger MR, et al. (2020) PTPN2 Regulates Interactions Between Macrophages and Intestinal Epithelial Cells ahead of print 2020 Jul 8. Gastroenterology S00165085(20)34922-2. doi.10.1053/igastro 2020.07 .004

2. Krishnan M, Penrose HM, Shah NN, Marchelletta RR, McCole DF. (2016) VSL\#3 Probiotic Stimulates T-Cell Protei Tyrosine Phosphatase-Mediated Recovery of IFN-gamma Induced Intestinal Epithelial Barrier Defects. Inflamm Bowel Dis. 22(12):2811-2823. doi:10.1097/MIB.0000000000000954

3. Sayoc-Becerra A, et al. (2020) The JAK Inhibitor Tofacitinib Rescues Human Intestinal Epithelial Cells and Inflamm Bowel Dis. 26(3):407-422. doi:10.1093/ibd/izz266

4. Shawki A, et al. (2020) The autoimmune susceptibility gene, PTPN2, restricts expansion of a novel mouse doi:10.1080/19490976.2020.1775538

5. Alvarez R, et al. (2019) A Simulated Microgravity Environment Causes a Sustained Defect in Epithelia Barrier Function. Sci Rep 9, 17531. https://doi. org/10.1038/s41598-019-53862-3

\section{Personal Response}

\section{What are the next steps for your research?}

II Our ongoing work is investigating more detailed molecular mechanisms by which loss of PTPN2 activity in mice and IBD patients genotyped for loss-of-function mutations, leads to disruption of key cellular structures (tight junctions) that govern permeability between epithelial cells. Tight junctions represent a critical target in conditions that weaken the intestinal barrier as they can be reorganised by inflammatory cytokines and bacteril wh path ogenic properties. Addilonal studies will detemine ff JAK inhibitors can be used to correct underlying gut barrier defects in mice lacking to treat specific patients. New NIH funding will allow us to determine additional mechanisms by which epithelial cells and intestinal immune cells (macrophages) act cooperatively to protect barrier function. 